
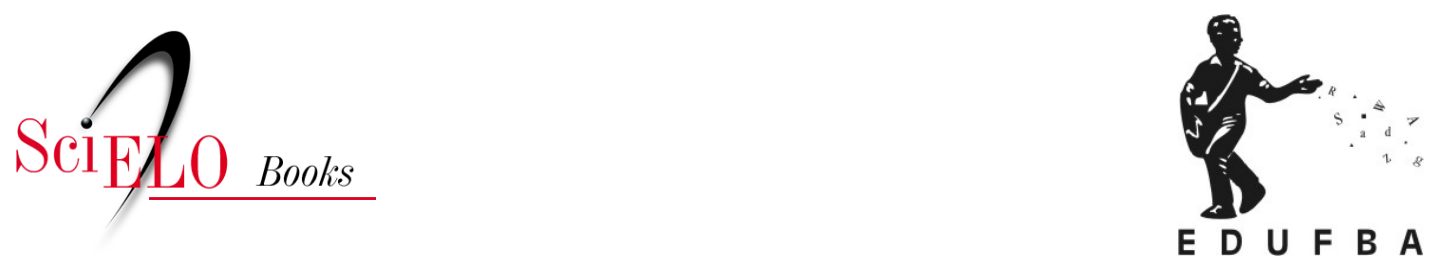

\title{
Prefácio \\ A festa de um abraço, a travessia de um encontro
}

Fábio Rodrigues Filho

\section{SciELO Books / SciELO Livros / SciELO Libros}

RODRIGUES FILHO, F. Prefácio - A festa de um abraço, a travessia de um encontro. In: CESAR, A., MARQUES, A. R., PIMENTA, F., COSTA, L., eds.

Desaguar em cinema: documentário, memória e ação com o CachoeiraDoc [online]. Salvador: EDUFBA, 2020, pp. 7-21. ISBN: 978-65-5630-192-1. https://doi.org/10.7476/9786556301921.0001.

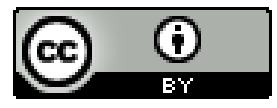

All the contents of this work, except where otherwise noted, is licensed under a Creative Commons Attribution 4.0 International license.

Todo o conteúdo deste trabalho, exceto quando houver ressalva, é publicado sob a licença Creative Commons Atribição 4.0.

Todo el contenido de esta obra, excepto donde se indique lo contrario, está bajo licencia de la licencia Creative Commons Reconocimento 4.0. 


\title{
A festa de um abraço, a travessia de um encontro
}

\author{
Fábio Rodrigues Filho
}

Inspirado por um acontecimento em 2016, no CachoeiraDoc, quando a júri ${ }^{1}$ daquela edição concedeu menção honrosa às vinhetas do festival, gostaria de instigar-nos a pensar uma pequena história das vinhetas do "Cachoeira". Acompanhando a transformação das vinhetas e as correspondências de signos em tempos distintos, talvez seja possível analisar alguns pontos importantes da história desse festival, especialmente da verve desse evento, através dessas imagens, que não só abrem as sessões como sobrevivem, articulando-se (entre elas) e preservando os enfoques de cada edição, numa configuração de momentos e, por conseguinte, da memória do próprio evento.

Para introduzir este livro, farei uma espécie de remix dessas vinhetas e, quando necessário, convocarei outras imagens que conformam registros das oito edições presenciais do festival - acervo que está disponibilizado na internet, ${ }^{2}$ e que guarda momentos que foram não só filmados, mas montados por diversos estudantes que compuseram, a um só tempo, a história do CachoeiraDoc e do curso de Cinema e Audiovisual da Universidade Federal do Recôncavo da Bahia (UFRB), com a qual o festival e este que vos escreve nutrem uma relação umbilical.

Esses estudantes - e devo dizer, colegas meus - semearam filmes, momentos e cenas que, felizmente, sobrevivem na memória, nas práticas e, não menos importante, nas imagens. Acompanhado desses dois regimes de arquivos

1 A júri, conforme a comissão se auto-intitulou, era formada pela pesquisadora e curadora Janaína Oliveira, pela professora e musicista Marina Mapurunga e pela produtora e curadora Marisa Merlo. Para saber mais: http://www.cachoeiradoc.com.br/2016.

2 Acervo disponível em: https://www.youtube.com/cachoeiraDoc. 
imagéticos, me lançarei a sondar vizinhanças e esboçar um comentário sobre o CachoeiraDoc e sobre este livro, desde o meu lugar de alguém que admira, colabora e, sobretudo, é atravessado pelas questões, imagens e encontros gerados pelo festival, assumindo, assim, a lente do amor - uma grande angular, como canta Gilberto Gil, como norte para essa costura textual. Não menos importante, esse modesto esforço ensaístico e, de certa forma, historiográfico, se valerá também de trechos dos textos de apresentação das oito edições do CachoeiraDoc. Portanto, entre trechos de imagens e dos catálogos, seguirei, aqui, como espectador e leitor do festival.

\section{Da ponte ao ponto}

Poderíamos pensar uma contiguidade entre uma das primeiras vinhetas do festival e o primeiro texto do catálogo, intitulado "Atravessando a ponte”, o qual evidencia a 'intuição motivadora' do evento e sua origem no deslocamento: "o desejo de provocá-lo e uma aposta na sua potência”. (CESAR, 2010, p. 3) Como nos 365 metros de ponte que liga Cachoeira a São Félix - extensão apropriada pelos cidadãos dessas cidades -, a ponte é ligação de diferenças e potência de aproximação das distâncias. Mais do que atravessar, a trajetória do CachoeiraDoc parece, ao seu modo, construir pontes, tornando o próprio evento uma ponte, dentre tantas outras presentes naquele lugar. Diferentemente da primeira, a ponte Dom Pedro II, já não se trata de uma ponte importada, mas gestada e nascida na fricção daquela cidade com as mudanças sociais e política impulsionadas no governo Lula (2003-2010), políticas de patrimônio e de interiorização da universidade pública e gratuita, que fez surgir também a UFRB, em 2005.

Mais do que atravessar, esse festival foi sendo atravessado. Como o rio Paraguaçu atravessa a ponte Dom Pedro, também o fizeram com o CachoeiraDoc filmes, pessoas, questões e mesmo a cidade, com seus dilemas, importâncias, história e desejos. Como na primeira vinheta, na qual atravessar é também inebriar-se por sua estrutura e arquitetura, a ponte e seu traçado tornaram-se a logomarca do festival e atravessaram o tempo.

Na mirada para esse acervo de vinhetas das oito edições, vão aparecendo correspondências entre as imagens: um gato a passar, o movimento das águas do rio, um passeio de canoa, a feira livre da cidade, a própria ponte etc. Signos que se diferenciam a cada reaparição. Pouco a pouco, também esses vídeos foram 
não só seguindo e intensificando o engajamento com as urgências do presente histórico, mas, sobretudo, reforçando e inscrevendo o desejo de participar das cenas cotidianas de Cachoeira, mais do que tê-las como cenário. ${ }^{3}$. Na cena da vinheta, após o preparo, vemos frontalmente o arremesso do coquetel para fora do filme: a um só tempo arremessado para o extracampo e para o extraquadro.

\section{Festejar, comemorar, celebrar}

Nas vinhetas, seja quando se retomam imagens de filmes - como no caso de Bicicletas de Nhanderú (Ariel Ortega e Patrícia Ferreira, 2011), em 2012 -, seja quando, por exemplo, se propõe a interação na feira livre de Cachoeira, há algo da energia engendrada (acentuada pelas trilhas musicais) que, parece-me, faz coro a, pelo menos, duas coisas latentes nos textos de apresentação do CachoeiraDoc. Primeiramente, é visível em sua programação o engajamento com o presente, a reelaboração do passado e as promessas de futuro, que se refletem num jogo de temporalidades engendradas pelos filmes e acolhidas na curadoria e no escopo do encontro. Uma energia transformada em prática curatorial, poderíamos resumir. A segunda característica latente, na qual vejo uma ligação mais direta, é a ideia de festa, quase sempre presente nos textos por meio de vocábulos variados: comemorar, celebrar, festejar...

O grito "vamos festejar” encerra o texto de apresentação no catálogo de 2010. (CESAR, 2010, p. 5) Nos anos seguintes, a mensagem continua: “[...] temos alguns motivos para celebrar, e um dos mais importantes deles é o conjunto de filmes que recebemos de realizadores do Brasil inteiro" (CACHOEIRADOC, 2011 p. 5); "festejemos, então, os filmes e, com eles, a invenção de modos de viver melhor nas cidades e no mundo" (CACHOEIRADOC, 2013, p. 9); "festejar" a formatura da primeira turma de cinema da UFRB, ou ainda "celebremos os filmes e suas apostas renovadas em novas formas de existir e resistir", foram os modos como a festa apareceu no catálogo de 2014 (CESAR, 2014, p. 5); "se o documentário pode ser festejado como um amplo campo de aprendizagem é porque seus limites institucionais não são jamais definidos por completo, é porque suas portas

3 “[...] queremos que o Recôncavo seja mais do que o cenário deste festival. Desejamos também que sua história, cultura e realidade façam parte das imagens e sons que mostraremos nas nossas telas e mais do que isso, que o povo desta terra esteja presente na plateia ou nos créditos dos filmes que exibiremos". (MARQUES, 2010, p. 6) 
estão e estarão sempre escancaradas à vida”. (CESAR, 2015, p. 6 Na crença de um projeto de futuro com os povos indígenas e seu legado de lutas e retomada, festejou-se a abertura do festival com a contundente fala e presença do cacique Babau. Festejar, enfim, um encontro em torno dos filmes para "fazer vibrar um compromisso com o futuro”, era uma das questões em 2016. (CESAR, 2016, p. 7)

Como nos lembra Pedro Severien em texto neste livro: no repertório de expressões dos movimentos sociais, festa é usado para se referir as ações de intervenção. Para o autor, a relação festa e ação direta se dá tanto por distrair a atenção de um possível algoz que perscruta o movimento, como para acentuar o caráter do gesto revolucionário que é eminentemente emancipatório, confrontador com a ordem estabelecida e celebrativo da vida.

Também na cidade de Cachoeira, a partir de sua história de luta, de seu território e terreiros sagrados, encontramos sentidos possíveis para ideia de festa. A festa, ali, sempre foi arma de luta (como no caso da festa d'Ajuda), produção de vida, preservação de legados, encontro entre diferenças, promessas de futuro, reescrita do passado e produção de dignidade no presente. Foi pela festa, enfim, que por vezes se deram os levantes e resistências. A festa aparece também como um possível aprendizado com a cidade e, ao seu modo, um esboço de inserção na dinâmica do lugar.

\section{Travessia}

Sugeri que há fagulhas nos textos dos catálogos do CachoeiraDoc que sondam ou mesmo arremessam-se a um futuro, a um extracampo - porque especulável -, e a um extraquadro - porque nos escapa. O futuro por vezes aparece como incerteza, quando, por exemplo, em 2014, ao completar cinco anos, fez-se um balanço e uma mirada intrigada: não porque o passado (muito próximo ainda) precise ser rememorado, mas porque há, e há de haver, um porvir, e ele se apresenta, agora, especialmente desafiador. Incerto também quando foi anunciada a pausa, em 2018, por falta de perspectiva de financiamento público para o festival. Mas o futuro também vem, nesses textos, como promessa: por exemplo, quando se calendarizou $^{4}$ o festival, garantindo-se quatro edições (2013-2016), ou na convocação,

4 Ver mais sobre no texto "Política cultural, financiamento e gestão de um festival de cinema", publicado neste livro.

10 - DESAguar EM CINEMA 
em 2019, para criar junto ao extracidade uma nova edição para o CachoeiraDoc - convocação que faz ponte para atravessar a pausa.

Certamente, essa promessa está imbricada numa concepção nutrida pelo festival em relação aos filmes: engajamento com o presente, compromisso com o futuro. (CESAR, 2016, p. 6) A formulação atenta-se a algo próprio dos filmes de intervenção - sua característica de ação (ou ações num campo amplo de outras ações), e de algo em relação à postura curatorial, relacionar-se com essas imagens como atos (sensibilidades em vida). ${ }^{5}$ "O que faz da obra sujeito?”, questiona Nicole Brenez em seu texto/carta neste livro. ${ }^{6}$ A provocação se desdobra em considerar, enfim, "A provocação se desdobra em considerar, finalmente, uma imagem como ato crítico, de modo, a estar atento às questões que cada filme propõe.” Não à toa, o termo "travessia”, empregado no subtítulo deste texto, é também referência direta ao título do filme de Safira Moreira (2017), que agencia um jogo de temporalidades ou, poderíamos dizer, articula "travessias entre passado, presente e futuro", como nos diz Amaranta Cesar. Essa travessia está nos filmes, marcadamente nesse de Safira, e numa história e prática curatorial que celebra, cultiva e faz circular uma energia. Nos parece que o modo como o festival faz respirar e renovar questões lançadas pelos filmes mantém uma energia de luta em circulação e em potência de enfrentamento.

Em 2016, por exemplo, perguntou-se: "Pode o documentário ser ele mesmo, um laboratório de memória? De que maneira os procedimentos cinematográficos investigam, resgatam e reelaboram experiências do passado à luz do presente?”. (CACHOEIRADOC, 2016, p. 12) Essa pergunta guia a relação com os filmes, mas também orienta uma prática curatorial de relação propositiva e prospectiva - "Talvez esta seja uma forma de arrancar do real e do pensamento geral um imaginário de comunhão e resistência”. (CESAR, 2016, p. 6)

Em nossa especulação, lançamos uma aposta. Em 2018, ano em que foi anunciada a pausa do CachoeiraDoc, ocorreu uma sessão especial do festival intitulada “Curtas para gerar o amanhã”. O repentino encontro se dava numa manhã de quinta-feira, no mês de outubro, fazendo um apanhado de filmes exibidos nas edições do festival junto ao curta-metragem Conte isso àqueles que dizem que fomos derrotados (Aiano Bemfica, Camila Bastos, Cristiano Araújo e Pedro

5 Ver "Imagem performativa, ação direta, desobediência: um cinema de ocupação", neste livro.

6 Ver "Papel da crítica: rememoração histórica e exigências contemporâneas", neste livro. 
Maia de Brito, 2018). Em seu título, o filme cita trecho de um poema do escritor palestino Najwan Darwish, no qual pede-se que sejam narradas novamente as histórias de um jovem leão, de um rapaz magro e bravo e de uma garota, três histórias de personagens que resistiram apesar de tudo, cada qual ao seu modo e em seu contexto-limite de uma situação de violência.

Ao manter-se firme, ao salvar-se de um esquadrão ou saltando pelo ar, as três histórias do poema, mais do que ensinar, acendem uma chama de esperança e de possibilidade de não aceitar a derrota como ponto final - lega uma energia e uma lição. ${ }^{7}$ A sessão única de curtas que, longe de ocupar a ausência da edição do CachoeiraDoc em 2018, mais forte demonstrava a irredutível falta do festival, amanhava uma promessa que só em 2019 emergiria como convocação - "Para tramar futuros: uma convocação” -, quando enfim a pausa ganhava fim e uma radical mudança no escopo do festival tentava não continuar aquilo que parou, mas retomar e reinventar-se junto.

Diria, enfim, que nesse festival há um sentido de formação que reside também na atenção à pedagogia das lutas e seus ensinamentos. Desse modo, ensina, repassa, amplifica e, a sua maneira, contribui, ao fazer circular essa energia e, sobretudo, potencializar seus ecos e ressonâncias. Assim, "curtas para gerar o amanhã" e a convocação para "tramar futuros” novamente acentuam um aprendizado com os filmes e com o tempo - tempo que é, ele mesmo, luta. (CESAR, 2017, p. 7) Acredito que o compromisso com o futuro que volta e meia aparece nos textos é também um engajamento na justiça, no fim de dores e de violências. Nisso, há algo sobre cultivar lições, semear alegrias e amanhar outros mundos "Trata-se de atuar no presente semeando as pistas que tornam possível um novo presente por vir". ${ }^{8}$ Aqui, no pensamento de travessia - jogo de temporalidades -, o atravessar em que começamos esse texto e, por conseguinte, o ser atravessado, como interpretamos a história do CachoeiraDoc, ganha uma inflexão decisiva.

7 Aquilo que o poema profere poderia ser resumido nas palavras de Amaranta Cesar, no texto "Conviver com o cinema: curadoria e programação de festival como ato de intervenção na história", neste livro: "as lutas ensinam ao cinema e às suas instituições que o chamado à ação que a história nos destina é um trabalho incessante que só aprendemos com a própria ação - nossa ação mas também e fundamentalmente daqueles que agiram antes de nós".

8 Cesar em texto publicado neste livro. 


\section{Para atravessar o abismo ${ }^{9}$}

Certamente, menos interessado nas fronteiras que demarcam o documentário enquanto gênero do que, justamente, nos alargamentos e deslocamentos para além dessa linha fictícia, o CachoeiraDoc esteve sempre disposto ao vigor essencial do documentário. Ainda, poderíamos pensar, o festival esteve menos interessado no conceito fechado do que nas potências de abertura, na relação entre filme e mundo, de modo a não subsumir o segundo pelo primeiro, mas justamente vê-los em incessante travessia. Não é difícil rastrear, ao longo do tempo, questões que foram colocadas, muitas delas como pontes entre filmes, mundo, pessoas, história e luta política, deslocando da questão "o que é?" para, justamente, “o que pode?” - inflexão de sentido e, essencialmente, de relação.

Em 2013, "O que podem os filmes diante do mundo?”, "O que quer dos filmes o mundo?” ou, ainda, “Que filmes merecem o mundo?”, "Que mundos merecem os filmes?”. (CACHOEIRADOC, 2016, p. 6) Em 2014, ao comemorar cinco anos de existência, ressoa no texto de apresentação do catálogo, a partir de uma pequena alegoria extraída da formulação de uma criança, a seguinte pergunta: "ficou adulto?" - questão retórica, de certo, da qual logo emerge o desejo de: "continuar provando de tudo [...] com o mesmo entusiasmo da novidade, entusiasmo de quem ouve, vê, toca e saboreia as coisas pela primeira vez". (CESAR, 2014, p. 4)

Em 2016, mais uma vez, em direta relação com um contexto político de brutalidade narrativa, golpe contra a presidenta Dilma Rousseff e "operação de uma maquinaria de violência simbólica e material": "O que podem os filmes? [...] Quando parece que temos pouco a dizer e fazer, que os modos de combate e reação soam ineficazes e envelhecidos, o que significa estarmos reunidas/reunidos em torno do cinema?”. (CESAR, 2016, p. 6)

Em 2017, o radical da questão é preservado mas com uma decisiva inflexão: "O que podem os filmes diante de tantos ataques concretos à vida e ao direito de vida digna?”. (CESAR, 2017, p. 6) A provocação se invertia, e perguntava também "o que podem essas lutas de justiça e dignidade social pelo cinema?" (Ibidem) - ou seja, há algo de inevitável e uma necessária transformação da própria compreensão do cinema que essas lutas precipitam. Mas as questões seguiram, a

9 Citação ao título do texto de apresentação da mostra competitiva da $7^{\circ}$ edição do CachoeiraDoc (2016), escrito por Amaranta Cesar, Ana Rosa Marques, Evandro de Freitas, Flora Braga, Laís Lima e Ulisses Arthur. 
despeito da pausa do CachoeiraDoc. Quando em 2018 anunciou-se a pausa, uma questão acompanhou o título: "pausa (é luta?)”. (CACHOEIRADOC, 2018) Devese notar que, nessa mesma ocasião, também uma dúvida reabriu a conclusão da nota pública: "Ao cinema negro e indígena, ao cinema das mulheres, ao cinema periférico e militante, para os quais a nossa tela se ergueu nesses oito anos, temos nos voltado para indagar: como resistir, reagir?”. ${ }^{10}$

De uma forma ou de outra, quase todos os textos reunidos neste livro são elaborados no ressoar de algumas questões lançadas por filmes que compuseram as edições do CachoeiraDoc. Esse é o caso do belo texto de Rosângela de Tugny e Bernard Belisário, ${ }^{11}$ a partir do filme Grin (Roney Freitas e Isael Maxakali, 2016), por questões lançadas pelo próprio festival ou por questões que o atravessam. No texto de Maria Cardozo, ${ }^{12}$ por exemplo, a autora nos diz: "Sigo me perguntando 'o que podem as mulheres para a legitimação e escritura histórica dos filmes de mulheres e de suas trajetórias?' e procuro caminhos para deixar ecoar esse questionamento", referindo-se à questão que guiou a vivência em curadoria com mulheres, em 2016. No texto da professora Jurema Machado, ${ }^{13}$ o ressoar também se apresenta de modo literal: “Até hoje, não passou um dia sequer sem que eu me recorde da conferência de abertura realizada por Babau [...] e da presença marcante de Makota Valdina na primeira fila da plateia. Questões e encontros que se desdobram”.

\section{Encontros que se desdobram}

Findando, por ora, esse rastreamento de algumas questões colocadas, visto que chegamos no agora em que esse texto se insere, devo registrar que escrevo essas palavras numa situação de isolamento social em que, por mais parado que esteja o corpo, a memória está em movimento. Percorro cartazes, catálogos, imagens e vinhetas e me deparo com a minha aparição em alguns dos vídeos, ora como espectador, na primeira edição de que participei, em 2013, ora mediando alguma sessão. Conheci o festival quando ele já era realizado no mês de setembro,

\footnotetext{
10 Nota pública, publicada em 2018, disponível em: https://www.facebook.com/docachoeiradoc

11 "Cantos, luto e resistência Tikmũ'ũn (Maxakali) no filme GRIN (2016)".

12 "Curadoria da perspectiva das mulheres".

13 "O futuro e os caminhos encantados: Cachoeira reencontra os Tupinambá".
} 
coincidindo ou antecedendo o feriado de independência do Brasil. Presenciei a mudança de local para o Cine Theatro Cachoeirano, reinaugurado em 2014. Como muitas colegas, experimentei diferentes funções no festival - da formação junto a estudantes de escolas públicas do Recôncavo Baiano à comissão de Júri Jovem, em 2017. Inevitável recordar a vibração da última edição do festival, edição incendiária que deixa suas marcas.

Como ilha de edição que é esse texto, operarei uma breve inversão com minha primeira memória no festival: seu Mateus Aleluia cantando no largo d'Ajuda após a exibição do filme A vida sobre a terra (Abderrahmane Sissako, 1999), num encontro luminoso entre a imagem do pôr do sol ao som de Salif Keita, em que vemos no campo de arroz Nana Baby seguir em sua bicicleta seu percurso para além da fronteira do próprio filme. Em seguida escutamos um show do glorioso filho do Recôncavo, seu Mateus Aleluia, que, ao lado de sua filha, entoava em praça pública "vamos celebrar o amor há de renascer das cinzas". Nessa história por citações que realizo aqui, caberia citar a pesquisadora Kênia de Freitas em um texto publicado no âmbito da intervenção do CachoeiraDoc em 2020, o "Festival Impossível, Curadoria Provisória”: ${ }^{14}$ "Nesse momento, só posso dizer que não sei. E lembrar novamente das palavras das parábolas de Butler: 'Para ressurgir das próprias cinzas uma fênix deve primeiro queimar’”. (FREITAS, 2020)

Ao pensar no presente em que esse texto é escrito, entre a incerteza dos próximos passos e a gestação de uma nova edição do CachoeiraDoc, recordo insistentemente da última sessão da oitava edição, a qual, aqui nesse livro, ganha uma análise especial a partir do olhar do professor Osmundo Pinho, em seu texto "Black border: o corpo e a luta no cinema negro". A sessão da mostra "Corpos em Luta” reunia seis filmes, quatro deles comentados de modo denso e preciso pelo autor. Caberia, por força do agora em que escrevo, tirar algumas implicações dos dois filmes que ficaram fora da análise, mas retornam aos meus olhos, dada a convocação do presente: Now! Again! (2014) e Monangambee (1968).

O primeiro, dirigido por Alex Johnston, retoma e se constitui como uma citação direta ao filme Now! (Santiago Alvarez, 1964), expondo a perversidade bárbara do racismo estrutural e do estado policial. Johnston reúne, dessa vez, flagrantes do levante negro em Ferguson, Missouri, em agosto de 2014, quando o jovem Michael Brown foi assassinado em uma abordagem policial. Nessa

\footnotetext{
14 Ver mais em: http://www.cachoeiradoc.com.br/festivalimpossivel.
} 
ocasião, surgiu o movimento Black Lives Matter, do qual emerge uma nova geração de ativistas afro-americanos. ${ }^{15}$ Em 2020, vimos a necessária e forte onda de protestos nos Estados Unidos, novamente com o Black Lives Matter, protestando e incendiando prédios e monumentos numa insurreição contra o covarde assassinato de George Floyd e, não menos importante, contra os monumentos e estruturas coloniais e racistas que seguem de pé. A frase "vidas negras importam" não só ecoa como se encarna na própria luta. As imagens dos protestos fazem o "Again" e a convocação à ação direta, o "Now", ainda mais patentes.

Quanto ao Monangabee, em abril de 2020, a diretora Sarah Maldoror morreu vítima de covid-19, a doença causada pelo novo coronavírus. A triste morte da cineasta, aos 91 anos, soma-se a outros tantos nomes de pessoas, de vidas, que foram perdidas neste doloroso episódio da história global. No caso do seu filme exibido, trata-se de uma adaptação do conto "O fato completo de Lucas Matesso”, de Luandino Vieira. Através da história de um dia da vida de Matesso, prisioneiro político em Angola, a quem a mulher faz uma visita e promete preparar-lhe um "fato completo", Sarah Maldoror "constrói uma metáfora de forte investimento sensorial para a brutalidade e distorções produzidas pela opressão colonial”. (CACHOEIRADOC, 2017, p. 72) A expressão "fato completo" (prato popular angolano), "pronunciada pela mulher em visita ao marido encarcerado, desperta uma paranoia nos guardas portugueses, que acreditam tratar-se de um plano de fuga e mantém o homem sob tortura”. (Ibidem) A certa altura do curta, num diálogo entre o protagonista e o lagarto numa cela de detenção, Matesso diz: "Tens fome, lagarto? Tu também tens fome? Como me vês? Como um animal. [...] O que não conseguem com o chicote e a tortura, creem poder obter com a fome, lagarto".

A fala de Matesso encontra a fala de Cacique Babau em seu texto presente neste livro: ${ }^{16}$ "olha, eles podem ser poderosos, mas eles gostam de guardar dinheiro. Nós precisamos estocar alimentos, água e manter a luta, que quando nós não tivermos fome, nós conseguimos lutar, mas com fome qualquer um vai se ajoelhar”. O texto de Babau é a transcrição de sua fala na abertura da oitava edição do Festival e do Colóquio Cinema, Estética e Política, realizado pelo grupo

\footnotetext{
15 O resumo do filme que coloco nesse texto é uma citação direta à sinopse escrita e publicada pelo CachoeiraDoc no catálogo de 2017.

16 “Existência e luta Tupinambá", por Rosivaldo Ferreira da Silva (Cacique Babau).
} 
de pesquisa Poéticas da Experiência (Universidade Federal de Minas Gerais UFMG). Como nos lembra Jurema Machado, na ocasião da fala de Babau, na primeira fileira da plateia estava Makota Valdina:

O entendimento entre eles era percebido através dos gestos corporais. Muitas vezes Babau falou se dirigindo e olhando para Makota, e ela todo o tempo mexendo a cabeça assertivamente. [...] Certamente ali entre eles passaram-se coisas que a nós escaparam. ${ }^{17}$

Sim, nos escapa e nos escapará, mas nos emana encanto, força de luta e memória pulsante. Sobre isso, André Brasil e César Guimarães nos dizem: “O encontro pode ser tantos quanto múltipla é a imanência do mundo: avesso à abstração, ele repercute, toca, respinga, desdobra-se para além dele mesmo: repetição, insistência; mas também diferença, abertura de caminhos”. ${ }^{18}$

Neste livro, o encontro entre os dois, Cacique Babau e Makota Valdina, volta a reverberar - seja na reunião de seus textos, seja no eco e desdobramentos de suas falas. De uma forma ou de outra, este encontro nos abre caminhos... nos abraça e emite lições.

\section{Aquele abraço}

No texto que abre este livro, ${ }^{19}$ Ana Rosa Marques nos diz: "tem algo de árvore no CachoeiraDoc”. A formulação sensível e precisa reforça o caráter formador e formativo do festival. Em um dos vídeos do acervo a que me referi no início deste texto, imagens feitas por estudantes que atuam como monitores no festival, vemos a própria Rosa conduzir um debate de uma sessão histórica e afetiva. Ela apresenta Guido Araújo, que, além de cineasta e figura central do movimento de festivais e mostras na Bahia, também é apresentado como seu professor (ela e Amaranta Cesar foram alunas de Guido na Universidade Federal da Bahia UFBA), tendo, no caso de Rosa, sua primeira experiência com cinema justamente na Jornada de Cinema da Bahia (1972-2012).

\footnotetext{
17 Em "O futuro e os caminhos encantados: Cachoeira reencontra os Tupinambá", neste livro.

18 Em "O Encontro com Makota Valdina", neste livro.

19 "Memórias de uma árvore empassarinhada: formação e extensão no CachoeiraDoc".
} 
Além de ser um reencontro entre professor e alunas, trata-se de um encontro de referências - vimos os curtas-metragens de Guido Araújo numa mostra chamada Clássicos do Real. Guido, ao longo de sua fala, nos diz que foi justamente olhando o movimento das águas do rio Paraguaçu que surgiu a ideia para fazer a Jornada de Cinema em Cachoeira, como também olhar o movimento das águas desse mesmo rio é perspectiva recorrente nas vinhetas do Cachoeira. Seguindo sua fala, as memórias da jornada incidem e um desejo se projeta: que não só o CachoeiraDoc prossiga, mas prossiga como a jornada. Nisso, o texto de Izabel Fátima Cruz Melo $^{20}$ nos dá a ver correspondências mais diretas entre esses dois eventos, embora tenham acontecido em períodos distintos: a ligação com Universidades públicas, "o estímulo ao caráter formativo do festival, o interesse pelo documentário e cinema militante”, a interrupção por conta do contexto político e, de modo mais especulativo, a própria sessão de abertura das primeiras edições desses festivais. É no abraço final, ao fim do vídeo, que a "herança" legada, herança afetiva inclusive, parece transbordar da imagem. Este abraço, demonstra o encontro, "a um só tempo, como encanto e história”. Um abraço formador, semente, travessia e, portanto, promessa de futuro.

Como nos lembra Fernanda Pimenta e Leonardo Costa, em seu texto também formativo sobre a produção de um festival como CachoeiraDoc, todos os festivais "de maior notoriedade e continuidade na Bahia ao longo de décadas têm em comum a interrupção das edições”, sobretudo pela instabilidade nas políticas públicas para a cultura. Se, por um lado, a dupla de produtores do CachoeiraDoc nos apresenta traços comuns no contexto da Bahia, o pesquisador e crítico Adriano Garrett, em seu texto, ${ }^{21}$ evidencia alguns traços singulares do festival no contexto nacional: a relação com a universidade; 0 recorte do cinema documental (pensando no âmbito do nordeste brasileiro); a fundação realizada exclusivamente por mulheres; e a localização fora de uma capital brasileira.

Como falei, escrevo entre a incerteza do amanhã e a gestação coletiva de uma nova edição do festival por vir. Convoquei imagens e memórias a fim de costurar um arranjo dentre tantos outros possíveis. Nesta relação entre traços singulares e comuns, campo e contracampo, encerraria essa parte, esse modesto texto que

20 "Percursos e convergências: caminhos de aproximação entre a Jornada de Cinema da Bahia e o CachoeiraDoc".

21 "A falta que me faz: as particularidades do CachoeiraDoc dentro da nova configuração de festivais brasileiros". 
me coube, dizendo o seguinte: quem fala CachoeiraDoc diz a cidade de Cachoeira - "E não é qualquer cidade nem é qualquer cinema”. ${ }^{22}$ Já em seu nome, vida e cinema se nutrem, não se separam. Não são poucas as implicações e responsabilidades desse nome que, mais do que intitular, guia e acolhe. Como nos diz Makota Valdina: “Tem momentos, como esse, em que a gente tem de estar na luta como água. A água vai pingando, pin, pin, pin [...]. Daqui a pouco, você vê que está tudo alagado". ${ }^{23}$ Seja no miudinho ou no embalo, no fluxo caudaloso ou no insuspeito transcorrer, nas idas e vindas renovadoras, vida longa ao CachoeiraDoc. Certamente, tem algo de água nesse festival e muito de Cachoeira nele.

\section{Referências}

CACHOEIRADOC: II Festival de Documentários de Cachoeira. 2. ed. Cachoeira: [s. n.], 2011.

CACHOEIRADOC: III Festival de Documentários de Cachoeira. Cachoeira: [s. n.], 2012.

CACHOEIRADOC: IV Festival de Documentários de Cachoeira. 4. ed. Cachoeira: [s. n.], 2013.

CACHOEIRADOC. PAUSA (éluta?). Cachoeira, 23 de abril de 2018. Facebook: Festival de Documentário de Cachoeira, @docachoeiradoc. Disponível em: https://www.facebook.com/docachoeiradoc/photos/ pausa-\%C3\%A9-lutamarielle-foi-executada-lula-est\%C3\%A1-presoasfor\%C3\%A7as-nefastas-se-alastram/1857758404298901/. Acesso em: 21 de out. 2020.

CESAR, Amaranta. Atravessando a ponte... In.: CACHOEIRADOC: Festival de Documentários de Cachoeira. Cachoeira: [s. n.], 2010. p. 4 e 5 .

CESAR, Amaranta. Existir e resistir. In.: CACHOEIRADOC: V Festival de Documentários de Cachoeira. 5. ed. Cachoeira: [s. n.], 2014. p. 4 e 5.

22 "É Cachoeira uma cidade antiga projetada para o futuro, uma cidade preenchida pelo desejo de encontrar o mundo e de ser atravessada por ele. E é documentário, um cinema que carrega o peso a leveza do mundo, um cinema impregnado pela vida". (CESAR, 2012, p. 4)

23 "Os terreiros e as imagens", neste livro. 
CESAR, Amaranta. Ver e saber. In.: CACHOEIRADOC: VI Festival de Documentários de Cachoeira. 6. ed. Cachoeira: [s. n.], 2015. p. 5-7.

CESAR, Amaranta. Engajamento no Presente, Compromisso como Futuro. In.: CACHOEIRADOC: VII Festival de Documentários de Cachoeira. 7. ed. Cachoeira: [s. n.], 2016. p. 6 e 7.

CESAR, Amaranta.Cachoeira e a pedagogia do tempo: construção e ruína. In.: CACHOEIRADOC: VIII Festival de Documentários de Cachoeira. 8. ed. Cachoeira: [s. n.], 2017. p. 4-7.

FREITAS, K. Relatos de uma curadoria provisória. CachoeriaDoc: Festival Impossível, Curadoria Provisória, 2020. Disponível em: <http://www.cachoeiradoc.com.br/festivalimpossivel/>. Acesso em: 21 de outubro de 2020.

MARQUES, Ana Rosa. "O documentário e o desejo”. In.:

CACHOEIRADOC: Festival de Documentários de Cachoeira.

Cachoeira: [s.n.], 2010. p. 6 e 7.

MARQUES, Ana Rosa.Por que Navegar. In.: CACHOEIRADOC: IV

Festival de Documentários de Cachoeira. 4. ed. Cachoeira: [s. n.], 2013. p. 11-13.

Obras audiovisuais:

MONANGAMBÉ. Direção de Sarah Maldoror. Angola: 1968. (14 min.). TRAVESSIA. Direção de Safira Moreira. Rio de Janeiro: 2017. (5 min.). 